\title{
Transposition: from disbelief, to confirmation, to implications
}

\section{J.R.S. Fincham}

Movable Genetic Elements. Cold Spring Harbor Symposia on Quantitative Biology, Vol.XLV, Parts 1 and 2. Pp.1,025. ISBN 0-87969-044-5. (Cold Spring Harbor Laboratory: 1981.) $\$ 130$ (US), \$156 (elsewhere).

IN THE Cold Spring Harbor Symposium of 1951, Barbara McClintock presented the first fairly full account of her data and ideas on "controlling elements" in maize. Her message can, with hindsight, be regarded as two-fold - first, that the maize genome contains elements capable of frequent transposition and, second, that such transpositions are likely to play an essential role in normal cellular differentiation. Even though it was the custom at the time to publish verbatim the discussion following each symposium contribution, no discussion at all is recorded after McClintock's paper. The reactions, or so one has heard from thuse who were present, mostly ranged from incomprehension to disbelief.

Barbara McClintock did not contribute to the 1980 symposium, but she was present and must have been gratified to hear the ample confirmation, compressed here into two tightly packed volumes, of her main concepts. In one respect only is her original picture apparently falsified. Whereas she linked the kind of genetic movement which she saw in maize with controlled cell differentiation, it now appears that there are two distinct kinds of phenomenon.

First, there are the almost randomly moving, arguably "selfish", sequences. These are stiil not characterized at the molecular level in maize (though this will probably not remain true for much longer), but a number of examples of what are almost certainly closely comparable DNA elements are known in two other eukaryotes, yeast and Drosophila. In Drosophila, indeed, so many have now been detected that one begins to feel the need for a proper taxonomy and system of nomenclature. Movable elements like these will probably turn out to be present in all organisms. They are not, to be sure, totally anarchic. Most of the time their replication and movement is held in reasonable check, sometimes by repressors which they code for themselves - what one might call molecular self-restraint. But they seem likely to be significant mainly as generators of genetic noise. The future exploration of their relationships with their host genomes will constitute almost a new subject intra-organism ecological genetics. As one group of papers makes plain, they bear an uncanny resemblance to the genomes of the retroviruses of mammals and birds.

Controlled and specific DNA changes are also well represented in these volumes, but as a totally separate set of cases. Pride of place must be given to the rearrange- ments of mammalian antibody genes during the differentiation of antibodyproducing cells. The 1980 state of play in this sensationally developing field was thoroughly aired in the symposium. More information is now available pointing to the mutational origin of at least much of the observed antibody diversity. But the main elements of the current picture are laid out here, including the mechanism of heavy-chain switching by DNA deletion and the production of both membranebound and secreted antibody by different modes of splicing at the RNA level (a way of diversifying gene products of which much more is being and will be heard).

Whether immunity is unique among vertebrate systems of irreversible cellular differentiation in requiring DNA rearrangement is not known; many of us are waiting or searching for the next case. It is, however, already clear that, among prokaryotes and unicellular eukaryotes, controlled inversions or transpositions of DNA segments are an important means of reversible cell differentiation. Yeast mating-type switching, documented here in great detail, is the best eukaryote example so far, but two papers on antigen variation in trypanosomes give promise of a second example of comparable fascination and greater practical importance.

Nearly all of the leading workers on movable DNA elements are represented in these volumes, including the Russian drosophilists who were, unfortunately, unable to be present in person. The production is up to the usual high Cold Spring Harbor standards. All of the Cold Spring Harbor Symposia have been good buys and many have been landmarks. This one ranks among the very best of them.

J.R.S. Fincham is Buchanan Professor in the Department of Genetics, University of Edinburgh.

\section{Face to face with the disposable computer}

\section{Simon Lavington}

\begin{abstract}
Minicomputers: A Reference Book for Engineers, Scientists and Managers. Edited by Y. Paker. Pp.505. ISBN 0-85626-188-2. (Abacus Press: 1981.) £32.50. Available in the US from Heyden \& Son, \$70. Interfacing Microcomputers to the Real World. By Murray Sargent III and Richard L. Shoemaker. Pp.288. ISBN pbk 0-201-06879-6. (Addison-Wesley: 1981.) \$14.50, £8.70.
\end{abstract}

COMPUTERS are now firmly part of the grammar of science. It is not just that programming has become a commonplace activity; the incorporation of small computers into experimental apparatus is now within the capability and budget of most scientists. With the advent of programmable electronics - microprocessors and their related chip sets there are few limits to what the enthusiast can do with small computers. Even the traditional experts, the computer science academics, the pompous data processing managers, the loquacious salesmen, are at last being circumvented by ordinary mortals who are willing to "have a go". Of crucial importance to the non-specialist is how to connect his equipment to a computer, or his own computer to a large one. The umbrella term "interfacing" covers such topics. Hardware and software techniques for interfacing are the principal themes of both the books under review, and they both tackle them in the context of small computer systems.

The book by Sargent and Shoemaker is typical of the new movement amongst computer users. It swings along with an informality which refuses to be slowed down by the odd gap in the authors' technical knowledge. It is a cook-book of tricks for getting the most out of a Z80 microprocessor and a handful of TTL chips, written by two professors of optical science who have obviously had a lot of fun doing just that. But from this springs its drawback also: if you do not already have at least a modest electronics background and an enthusiasm for assembler programming, the book is nothing but gibberish.

In contrast, the collection of papers assembled by Dr Paker is written by experts. It looks at the general rather more than the particular, and is in the best traditions of textbook turgidity. Its big drawback is that the material derives from courses of lectures given some years ago and, though claiming to be "updated, reedited and condensed", shows its age in some of the technical details. Fortunately, many of the principles expounded transcend the fleeting years and the book could find a respectable home in the reference section of a library. It is best regarded as a series of review papers with special reference to minicomputers in real time and process control. The chapter on the CAMAC standard interface is particularly useful.

How is it possible that two books, both dealing with interfacing to small computers, should contain so much mutually exclusive material? Apart from the different time-references of the material covered, there is a more subtle reason which relates to the antecedents of 